\title{
Study on Difficulties and Countermeasures of Implementation of Replacement Training Program for County Teachers Training Team in National Training Program
}

\author{
Jigang Zheng ${ }^{1, a^{*}}$ and Jingmei Zhang ${ }^{2, b}$
}

${ }^{1}$ College of Vocational and continuing education,Baoshan College,Baoshan, Yunnan,678000,China.

${ }^{2}$ Library of Baoshan College,Baoshan, Yunnan,678000,China.

a6913641@qq.com, ${ }^{\mathrm{a}} 279619568 @ q q . c o m$

\section{Keywords: National culture plan; Training team; Research on countermeasures}

\begin{abstract}
According to the county teacher training team of the Baoshan college, the county teacher training team replaced the research project, summed up the intentional experience of the project implementation, analyzed the existing problems in the project implementation, discussed the countermeasures, and promoted the "national culture plan" more effectively.
\end{abstract}

\section{Introduction}

The national training program for primary and middle school teachers, referred to as "the national training program", is fully implemented by the Ministry of education and the Ministry of Finance in 2010. It is an important measure to improve the overall quality of primary and secondary school teachers, especially the rural teachers ${ }^{[1]}$.The plan of national culture includes two contents of "primary and middle school teacher demonstration training project" and "central and Western Rural backbone teacher training project". Through the innovative training mechanism, it adopts the combination of backbone teachers' off-line training, centralized training and large-scale teacher distance training, which is targeted to the backbone teachers of rural compulsory education in the Western China. Professional training ${ }^{[2]}$. The training projects of the backbone teachers in the middle and west rural areas include five projects, such as the county teacher training team, the replacement of production and the training, the training of the rural teachers, the training of the village teachers, the village school (Garden) and the teacher's network study.

\section{Project Background}

The Education Department of Yunnan Province, in combination with the relevant documents of the Ministry of education, the notice of the office of the people's Government of Yunnan on the publication of the Yunnan provincial teacher support program (2015-2020 years) (No. 110) and the relevant document spirit of the Provincial Education Hall, will improve the professional knowledge and comprehensive quality of the teachers and improve the modern educational thought. Thinking, ideas and methods, give full play to the demonstration and leading role of "national culture plan" project in primary and secondary school teacher training work, and combine the actual situation of Yunnan Province, formulate the "national culture plan" Yunnan project invitation (invitation) standard announcement.

The county-level teacher training team replacement and removal of production and training projects in the project county branch, sub study section, sub field selection of outstanding primary and secondary school teachers, teaching and research staff, full-time trainers to colleges and universities to participate in the 18 week (126 days) for three school years of sectional off-line study. In accordance with the proportion of trainees and normal students 1:1, institutions of higher learning select excellent normal students from senior grade to project county for 18 weeks of practice and practical teaching activities. The trainees take off 6 hours a week (42 days) each year and divide them into upper and lower classes. Among them, the city quality county-level teacher development center and the "shadow teacher" practice time of "shadow teachers" in primary and secondary schools are 1/3, and the rest of the time in Colleges and universities to carry out 
centralized study and summary and promotion. Colleges and universities in conjunction with network training institutions provide training network workshops for teachers participating in training, and carry out network training throughout, for a total of 80 hours. During this period, institutions of higher learning continue to follow and guide each year to the project counties to implement first-line teaching problems on-site collaborative research and on-site training guidance 2 times, 3 days each time.

\section{The Experience Effect of Project Implementation}

The school established the office of "national culture project" (abbreviated as "state culture office"), in charge of overall responsibility for the project of "national culture plan", and implement the project implementation "organized guarantee, department management, special person responsible, system standard", and carry out the whole process and meticulous management. The "state training office" is connected with the two level education administration department of the city and the county and the teacher education school. The project is carefully organized and organized and coordinated, and the discipline instructors and managers are arranged in the county of the permanent project. The teaching plan is completed carefully, including the arrangement of teachers, the arrangement of teaching activities, the supervision of teaching and the assessment of the quality of teaching, and the assessment is carried out separately in the two stages of the training and the practice of returning to the post. The use of project funds and the management of reimbursement will be unified and supervised by the "country training office", and the project funds are managed in accordance with the program. The financial management, supervision and review of the project is carried out by the finance department, and the audit of the project funds is carried out by the discipline inspection and review.

Further optimize the list of expert library. According to the students' professional field which is reflected in training and training experts, our university will join experts, scholars and senior teachers of local key primary and secondary schools in the field of higher education and research institutions in more disciplines, and set up a high level of training team to meet the students. The learning needs of sampling can reach the high level and high quality training requirements of the "national training program". Trainees are the backbone of teaching and have strong teaching practice ability, but the theoretical foundation is relatively weak, which leads students to be more interested in practical courses. In order to promote the all-round development of students, the course setting not only strengthens the operability and interactive participation of the course of subject teaching and practice ability, but also close to the inner needs and interests of the students, and strengthens the innovation of the curriculum and rationally configuring the theoretical course. In addition to the normal bulletin and the propaganda, we should invite the local television stations and the mainstream media to make corresponding reports on the "national culture plan", to a certain extent, propagandize the "national culture plan" and enhance the influence of the University.

To further optimize the training content, according to the experience of the past years and the feedback from the trainees, a serious reflection and research are carried out on the phenomenon that the content of the training content appears in the anonymous evaluation of some class contents, and the content of active and cooperation with the teaching experts is carried out in advance in a series of communication, and the efficiency of training is promoted and realized. The differences are complementary, promoting the exchange of trainees and teaching experts, enriching the training content, and extending the classroom to extracurricular activities, and carrying out a series of outdoor teaching activities.

Further increase the publicity of "national training program", enhance the enthusiasm of participants in learning, enhance the consciousness and enthusiasm of participating training, conscientiously study and deeply comprehend the spirit of "national culture plan", understand the aim of "national culture plan", clear the training goals, set up a plate of chess consciousness, and consciously shoulder the speed of education reform. The responsibility and mission of leather development should make its due contribution to improving the quality of the "national training program". On the basis of the preliminary investigation, the project county selects the subject which 
urgently needs to be sent to the countryside. It aims at establishing the county teacher training team, solving the actual problems in the teaching and teaching of rural teachers, and improving the classroom teaching ability of the rural teachers.

\section{Project Implementation Problems and Countermeasures}

The level of trainees is uneven, and few of them are enthusiastic about learning. Increase the publicity of "national training program" to make students clear the meaning and purpose of "national culture plan", enhance the consciousness and enthusiasm of participating in the training, conscientiously study and deeply comprehend the spirit of "national culture plan", understand the aim of "national culture plan", clear the training goal, set up a plate of chess consciousness, and consciously shoulder the speed of speed. The responsibility and mission of education reform and development will make its due contribution to improving the quality of the "national training program". It is the backbone of the kindergarten and primary and secondary school, and the backbone of the teaching. Most of the students shoulder the experimental class, the teaching of the graduating class and the work of the class teacher. The students can only do some auxiliary teaching work for the students. How to ensure that the trainees can not only be relieved to learn from labor, but also guarantee the quality of the work of teaching and class teachers. It is still necessary to work together in the province and undertake the joint research of the University and the project county.

Most of the students who participated in the project were faced with teachers' posts, civil servants, career posts and other examinations. There was conflict between the review time and the work time. In order to avoid the progress and quality of the "national training program", it is hoped that the provincial government will publish relevant documents for the written examination or interview for the students to participate in the teacher's Post Examination (such as the basis for issuing relevant country certificates as the basis for the interview or bonus), or to select non graduating students to the project county.

There is conflict in the time of teaching foreign experts. Foreign experts are more famous experts in the field of discipline, they all have more heavy teaching and scientific research tasks, but also go out to lecture, so there are some experts in the time of teaching conflicts. In order to alleviate the conflict in the time of teaching foreign training experts, the list of alternative experts is set up, the famous experts and scholars from universities and research institutions in and outside the province and the senior teachers of the local key middle schools are added to the list to alleviate the shortage of experts at the peak of the training period.

\section{Conclusion}

Through the implementation of the national training program, the linkage mechanism between universities and primary and secondary schools should be established to form a partnership, resource sharing and long-term communication, so that teachers' colleges can understand the requirements of teachers in primary and secondary schools more deeply and promote the reform of teaching in normal colleges and universities so as to achieve a win-win goal.

\section{Reference}

[1] National level teacher training in primary and secondary schools [EB/OL] .http://old.moe.gov.cn

[2] Zhang Kunxiang.Performance Evaluating Model for Short-term Training in National Education Training Program[J].Journal of QuJing Normal Nniversity,2011,30(06):101-104.

[3] Peng L, Xiaoping Z. Social Stratification and Cooperative Behavior in Spatial Prisoners' Dilemma Games [J]. PLOS ONE, 2015, 10(7): e0131005.

[4] M. Pla, P. Hernández, B. Ari?o, J.A. Ramírez and Isabel Díaz: Food Chemistry, Vol. 100 (2007) No.1, p.165.

[5] R.R. Pullanagari, I.J. Yule and M. Agnew: Meat Science, Vol. 100 (2015), p.156. 
[6] Saudland, A., Wagner, J., Nielsen, J. P., Munck, L., N?rgaard, L. and Engelsen, S. B: Applied Spectroscopy, Vol. 54 (2000) No.3, p.413.

[7] Balabin, R. M. and Smirnov, S. V: Analytica Chimica Acta, Vol. 692 (2011) No.1-2, p.63.

[8] Leardi, R. and N?rgaard, L: Journal of Chemometrics, Vol. 18 (2004) No.11, p.486.

A. Teixeiraa, A. Oliveira, K. Paulos, A. Leite, A. Marcia, A. Amorim, E. Pereira, S. Silva and S. Rodrigues: Small Ruminant Research, Vol. 126 (2015), p.40.

[9] H.W. Su, S. Kun, L. Zhang, Q. Zhang, Y.L. Xu, R. Zhang, H.P. Li and B.Z. Sun: Meat Science, Vol. 98 (2014), p.110. 